\title{
The latest technical solutions in rail vehicles drives
}

\author{
Maciej Andrzejewski ${ }^{1,}$, Dawid Gallas ${ }^{1}$, Pawel Daszkiewicz ${ }^{1}$, Agnieszka Merkisz-Guranowska ${ }^{2}$, and Hanna Stawecka $^{1}$ \\ ${ }^{1}$ Rail Vehicles Institute TABOR, ul. Warszawska 181, 61-055 Poznan, Poland \\ ${ }^{2}$ Poznan University of Technology, Faculty of Machines and Transport, ul. Piotrowo 3, 60-965 Poznan, Poland
}

\begin{abstract}
The article discusses the latest trends and solutions used in the offers of rail vehicles manufacturers. The study is mainly concerned with the technical solutions used in hybrid rail vehicles, whose development has become one of the priorities for the development of rail vehicles in the European Union in recent years. Stricter emissions standards for harmful compounds in the European Union have forced manufacturers to use increasingly sophisticated technology, including hybrid drives and alternative fuels. The products and solutions offered by the major manufacturers on the market, along with their capabilities and future applications are described. The predicted trends in the development of propulsion technology for rail and road-rail vehicles are also indicated in view of the current legislative aspirations among the EU Member States.
\end{abstract}

\section{Introduction}

From the invention of rail transport and rail vehicles their drive systems have evolved the most of all modern forms of transport. From steam engines through diesel engines and electric motors all the way to alternative drive technologies, hybrid drives and drives based on fuel cells. There are certain advantages to rail vehicles that makes them more compatible with a wider variety of drive systems. This serves as an explanation why rail vehicles were more likely to see innovations in vehicle propulsion technology tested on them so often. This is all mostly due to the right restrictions on size, weight, power, fuel types, and operating parameters for the engines of rail vehicles. Cars were not able to use the early steam engine technology effectively, although steam-powered cars have been tried. The overall size and weight requirements for an efficient steam engine have made the solution simply not viable. Steam engines have also been tried on planes, but again, due to their relatively high weight to power ratio this was done mostly as a proof of concept than a viable solution. As a result in transport steam engines have only seen widespread use in rail vehicles and ships [1]. Drive systems and engine units that are either too big for standard road vehicles, too heavy for airplanes, or too low power for ships $[2,3]$ can all find middle ground use in rail vehicle propulsion in some forms. Today rail transport is still boasts a huge variety of drive system types among all means of transport. Thus testing new drive systems and new fuel types happens commonly in rail vehicles, enabling manufacturers to test the economic viability and technological reliability of their novel ideas and new advanced propulsion technologies. While the majority of rail vehicles are equipped with either electric drives or conventional high-power CI combustion engines attempts have been made to test the less obvious solutions in hopes of finding more modern alternatives. This effort is mostly driven by a combination of economy and ecology, and is forced by the legislations passed in many countries around the world.

The rail vehicle drives currently in use rely primarily on fossil fuels [4]. This is a limitation that directly contributes to the emission of harmful compounds to the atmosphere. In addition to carbon dioxide, these include carbon monoxide, hydrocarbons, nitrogen oxides and particulate matter. The European Union's new and more stringent Stage standards are characterized by a reduction in emissions limits in each successive version (Fig. 2). Meeting these limits requires high-tech solutions inside the engine as well as aftertreatment solutions. Unfortunately, these solutions have limited ability to reduce emissions of harmful compounds, additionally their introduction is economically viable only to some extent. Moreover, continuous changes to the limits would require regular modifications and upgrades to the systems in use. To meet these challenges, as well as to improve air quality and reduce emissions, a more complete solution would be to use electric drives, or in cases where the internal combustion engine is necessary, hybrid drives. The most modern types of hybrid drives can significantly reduce the harmful emissions from internal combustion engines, thus allowing them to operate in accordance with the described standards [5]. An example of such a solution is the hybrid rail vehicle called "Evolution Hybrid" (Fig. 1), offered for purchase by General Electric.

There are many barriers to the introduction of stateof-the-art technology for rolling stock vehicles in the EU. Apart from costs or emissions reduction, it is necessary to take into account the laws and technical

Corresponding author: m.andrzejewski@tabor.com.pl 
specifications required by individual member states. In addition, vehicles and solutions in manufacturers' offers must meet not only the current emissions or safety requirements but also take into account possible future changes. As the average life span and operating life of rail vehicles is relatively high, the investment and costs incurred by the train operator must be justified, whereas the purchase of vehicles whose exploitation after a few years may cost the operator more than the manufacturer intended is undesirable. Hence many manufacturers of rail vehicles and vehicle drives are planning their commercial offers from the perspective of technologies that are just now entering the market. Examples include the latest hydrogen-fueled fuel cell technology. These are solutions that in their present form are too expensive to use individually or sporadically. It is certain, however, that as the infrastructure develops, these solutions will become increasingly competitive with today's conventional drives. And while a complete overhaul of all rail vehicle drive systems is neither economically viable nor financially feasible at this time, mostly due to the lack of sufficient support and supply for the new drive systems, as well as their proper maintenance and the necessary infrastructure, these new technologies are still an important indicator of the current trends in the development of rail vehicles.

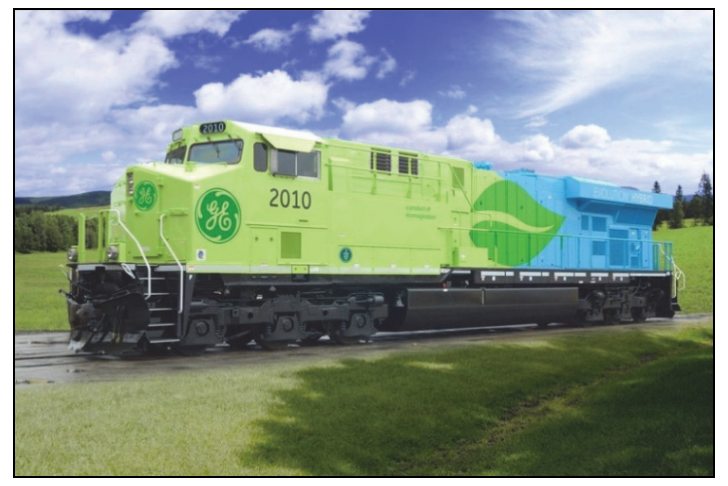

Fig. 1. Hybrid locomotive on offer from GE [6].

\section{The available hybrid drives}

\subsection{Modular systems}

Among the available solutions there are modular constructions, which allow for the choice of the drive system elements depending on the client's needs. With the battery system for powering the electric drive, it is also possible to use the pantograph to power the traction where available, provided the battery technology has a sufficient capacity and lifespan [7].

One of the main disadvantages of modular systems is the problem of properly utilizing all the available space. Ergonomics in modular solutions must be adapted to include the ability to change and select any module so that it can be integrated into a functional unit. Manufacturers more often offer modular systems for rail vehicles, rather than conventional freight or passenger locomotives. One of these vehicles is the Modalrac rail vehicle made by Schalke. It offers a choice from a range of power supply and drive solutions, including CI engine, battery pack, pantograph system and third rail power supply (Fig. 3). This allows a significant extension of the operational range for modular rail vehicles. The key feature offered by the manufacturer is the ability to exchange the selected module for another within the span of 60 minutes. This allows the rail vehicle to be used with a set of modules chosen based on the needs and limitations relating to the assigned task. It means that when working in urban or populated areas for example, the vehicle can be powered using the energy stored in the batteries or through pantographs, while work performed further in the field or off the grid would be performed when powered using a conventional CI engine. The option of making such modifications translates directly into a reduction of both harmful components and noise emissions in the populated urban areas, reducing the inconvenience as well as the health hazard posed to the local population.
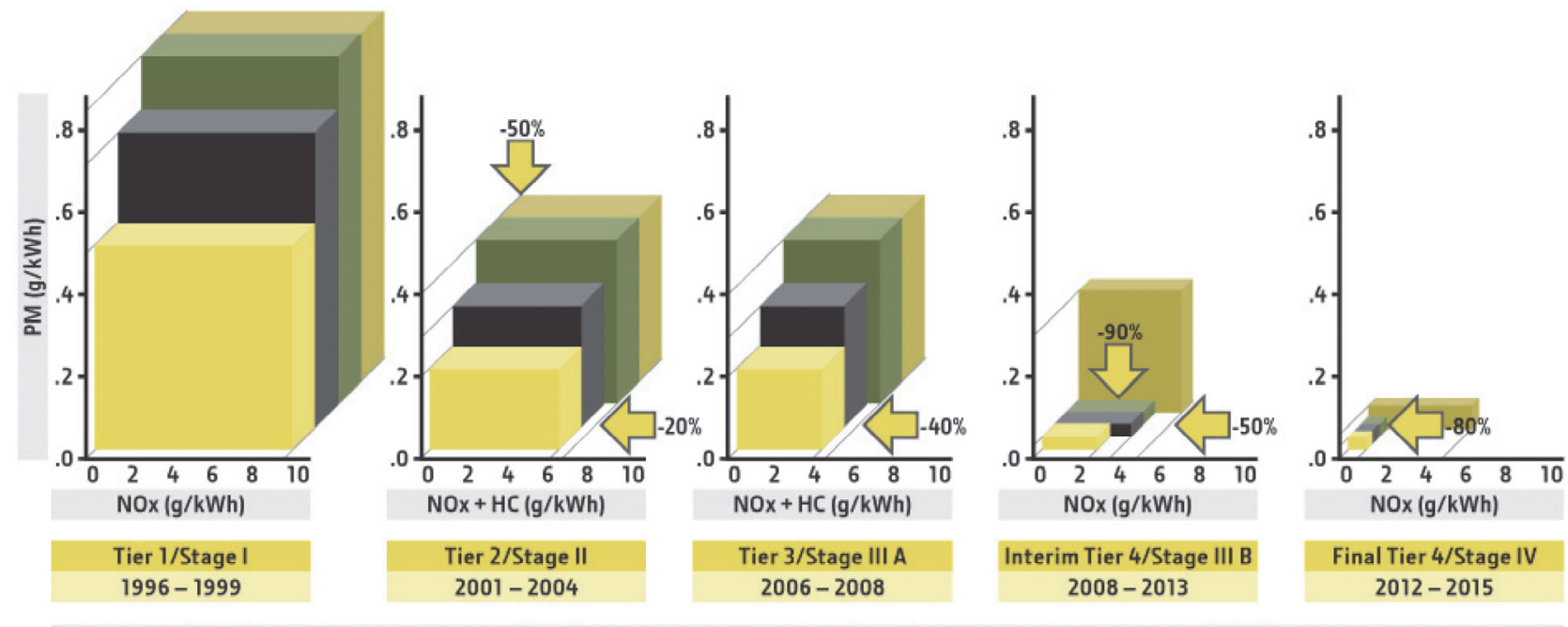

LEGEND:

$37-55 \mathrm{~kW}(50-74 \mathrm{hp})$

$56-74 \mathrm{~kW}(75-99 \mathrm{hp})$

$75-129 \mathrm{~kW}(100-173 \mathrm{hp})$

Final Tier 4/Stage IV $2012-2015$

Fig. 2. Emission standards for toxic exhaust gases of non-road vehicles according to John Deere in UE and EPA [8]. 


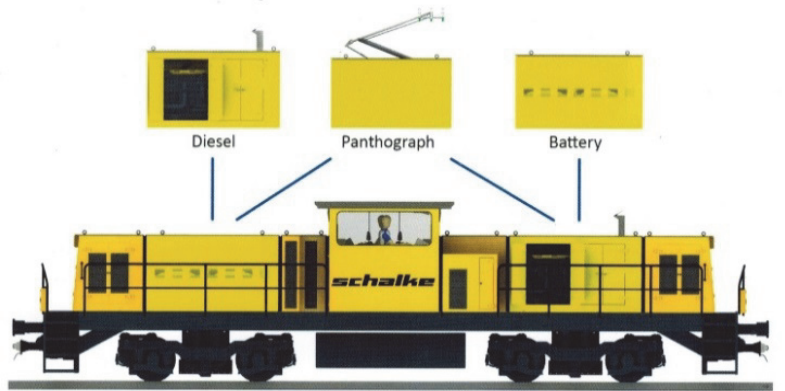

Fig. 3. An example of a specialist rail vehicle equipped with a modular drive system [9].

MTU has developed a modular hybrid drive unit for rail buses (Fig. 4 and 5), consisting essentially of an internal combustion engine (1) and a set of highefficiency energy storage units $(6,7)$. These trays can be located both on the roof of the vehicle as well as in its frame. In addition, the assembly includes an electric motor (2) with a power transmission (3). In order to meet the current European Stage IIIB emission standard for Non-Road Mobile Machinery (NRMM) most vehicles need to be tested extensively and require aftertreatment systems and engine modifications [10-13]. In comparison this vehicle is equipped with a technologically advanced selective catalytic reduction system (4), which is used to reduce the nitrogen oxide content of the exhaust gas using a urea solution, under the commercial name AdBlue (5 - tank with this liquid). The extended control unit (8) oversees the correct operation of the entire propulsion system.

The MTU hybrid drive unit can operate in 4 modes. The first mode is to drive using only an internal combustion engine (Fig. 6a). When the demand for energy rises (greater movement resistance), an electric motor powered by high-efficiency energy storage is additionally activated by the control unit. In situations where low emission of pollutants in exhaust gases (passage through highly urbanized areas, tunnels, operation in railway stations) is required, the energy needed to drive the vehicle is derived only from the above mentioned batteries (Fig. 6b). The fourth mode of operation of the MTU drive unit is the recuperative braking mode, during which the energy storage units are charged (Fig. 6c).

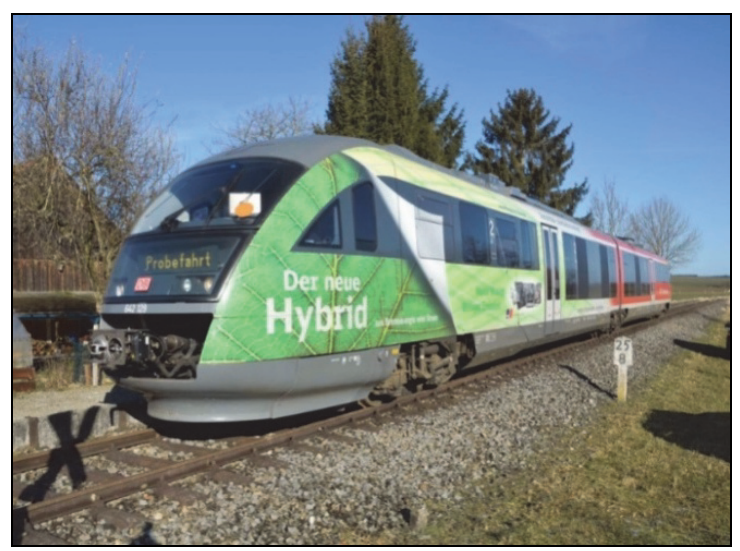

Fig. 4. Hybrid drive railbus from MTU company [14].

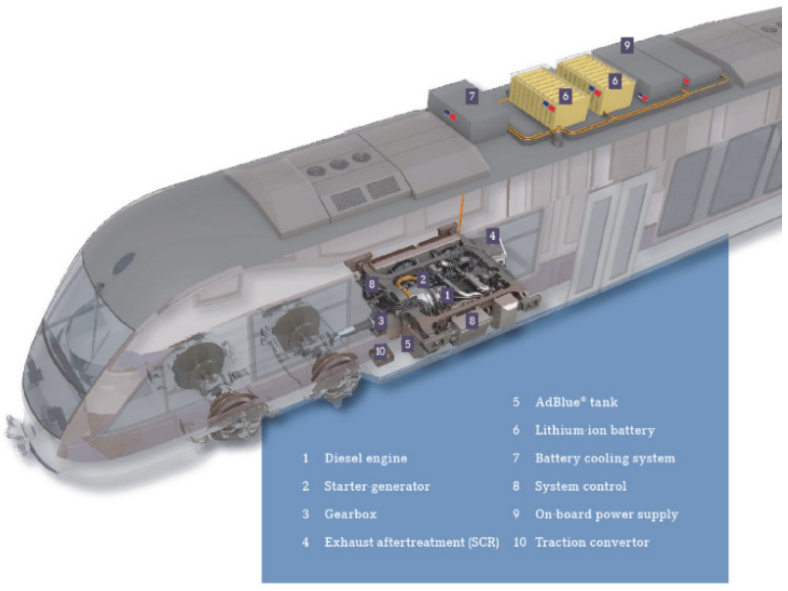

Fig. 5. Hybrid drive system used in the VT 642 rail bus [14].

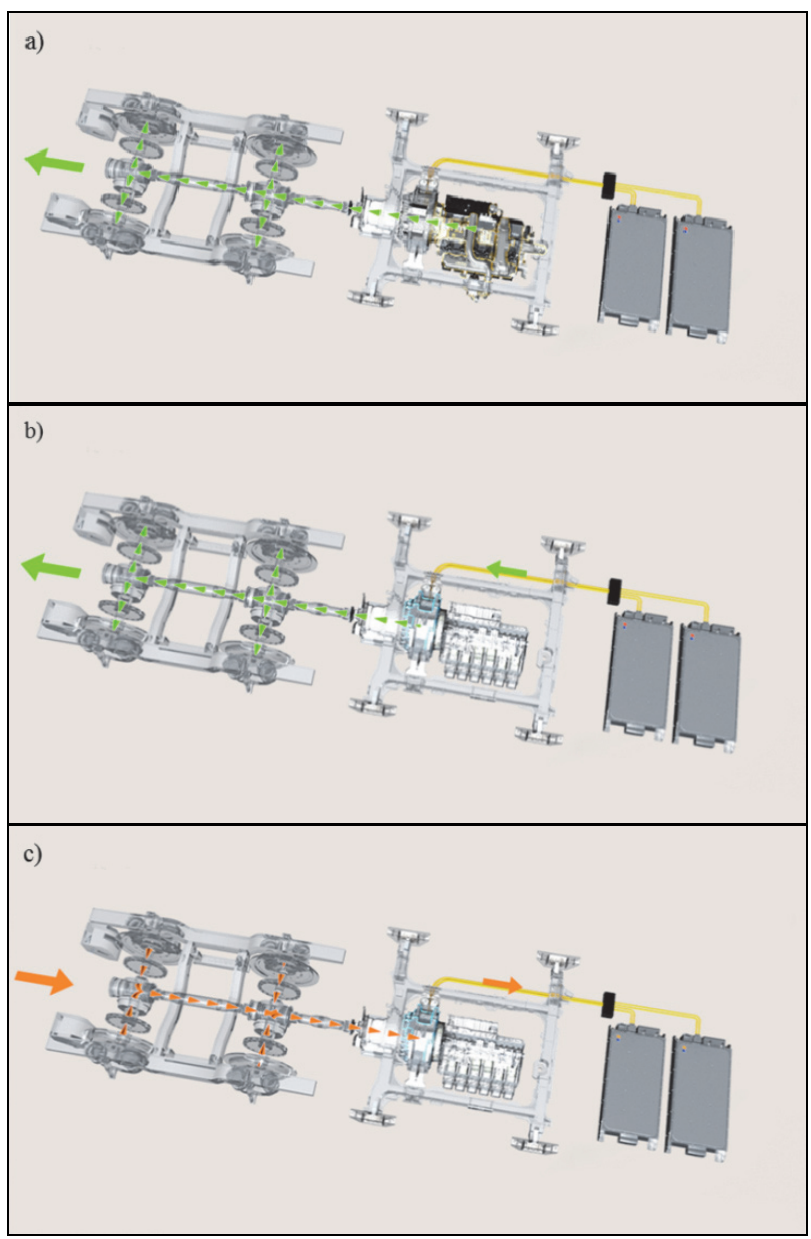

Fig. 6. Selected modes of MTU hybrid drive system operation [14]: a) driving mode - power supply from internal combustion engine, b) driving mode - power supply from batteries, c) recuperative braking mode - charging batteries.

\subsection{Types of hybrid drives}

In rail applications, the same type of hybrid drive division is used as for road vehicles. Series hybrid and parallel hybrid drives are offered as standard. Examples include hybrid drives provided by Toshiba that offer complete solutions for series and parallel-series drives for locomotives. 
The series hybrid drive is used in some rail vehicles, where it allows the engine to be stopped while the vehicle is stationary instead of leaving it idle. This solution, similarly to the start-stop system known in road vehicles, significantly reduces or even eliminates the share of operating time of the CI internal combustion engine spent in the operating areas responsible for the most significant part of harmful compounds emissions. In this case, the use of an electric drive avoids the need for the engine to run continuously. Series is the most rational solution, because the internal combustion engine can operate at a narrower speed range, thus speed and load changes can be avoided so that the engine runs with its optimal parameters [5]. The solution offered is a full drive system, including batteries (Fig. 7). This arrangement also allows for the recovery of some of the energy during the braking process [15], increasing the overall vehicle efficiency (Fig. 8).

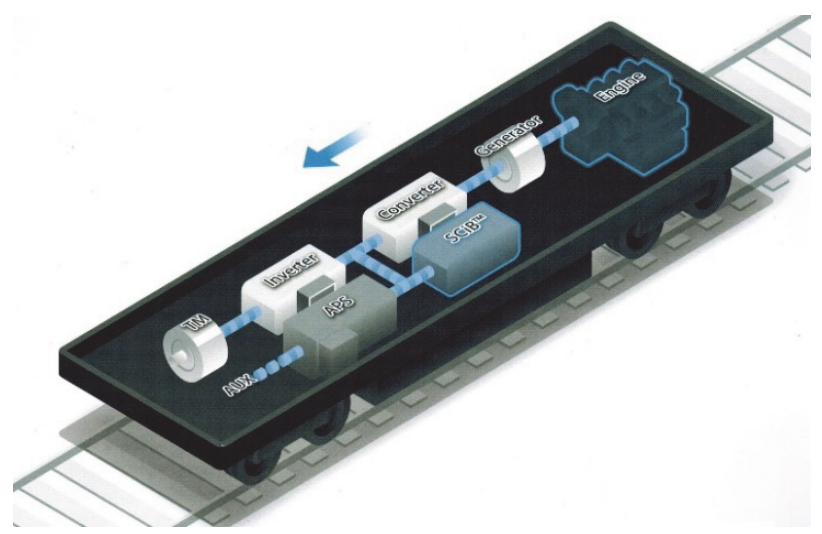

Fig. 7. Series hybrid drive system offered by Toshiba [16].

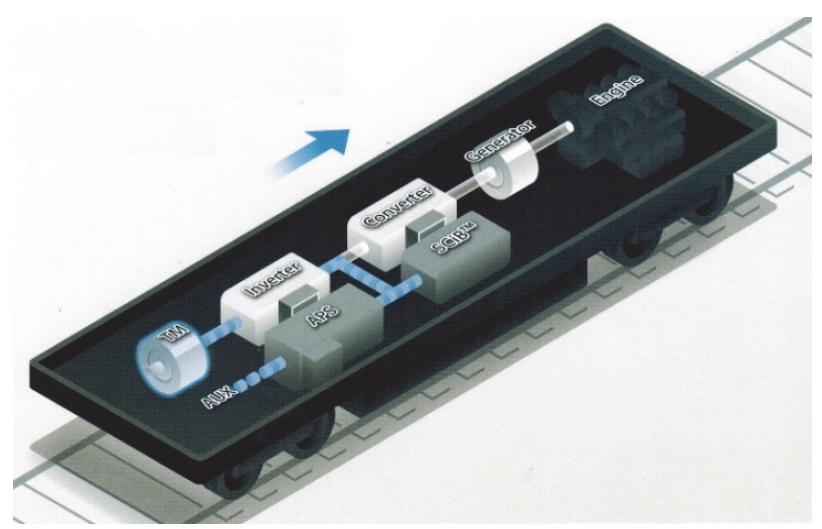

Fig. 8. Energy recovery using a hybrid drive offered by Toshiba [16].

Tests of this solution performed by the manufacturer have shown that the use of a series hybrid drive reduces emissions of nitrogen oxides by $61 \%$, noise emissions by $22 \%$, fuel consumption by $36 \%$, as well as reducing the operating and maintenance costs of the vehicle. This is a significant improvement with respect to conventional drives, especially given the difficulty in achieving greater emissions reduction improvement through standard exhaust gas aftertreatment solutions. Including those performed using retrofitting.
Similar solutions are used in special-purpose rail vehicles. Platform Basket uses a hybrid serial drive to power its road-rail vehicle for work on electrical traction or other difficult to reach places (Fig. 9). This solution uses two inver connected to two electric motors. One of the electric motors drives the vehicle, while the other powers the arm (Fig. 10).

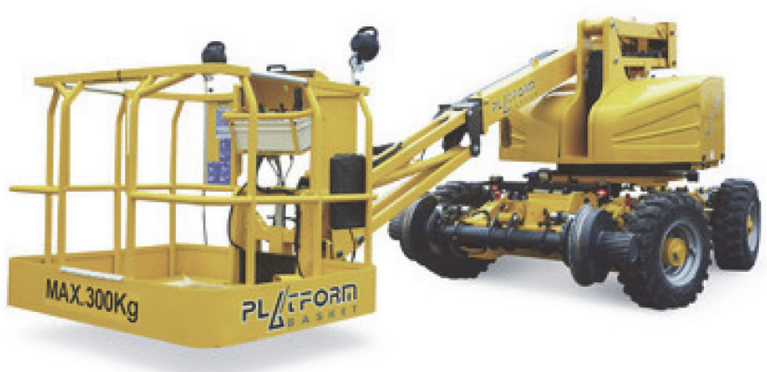

Fig. 9. Road-rail specialist platform with a hybrid drive system by Platform Basket [17].

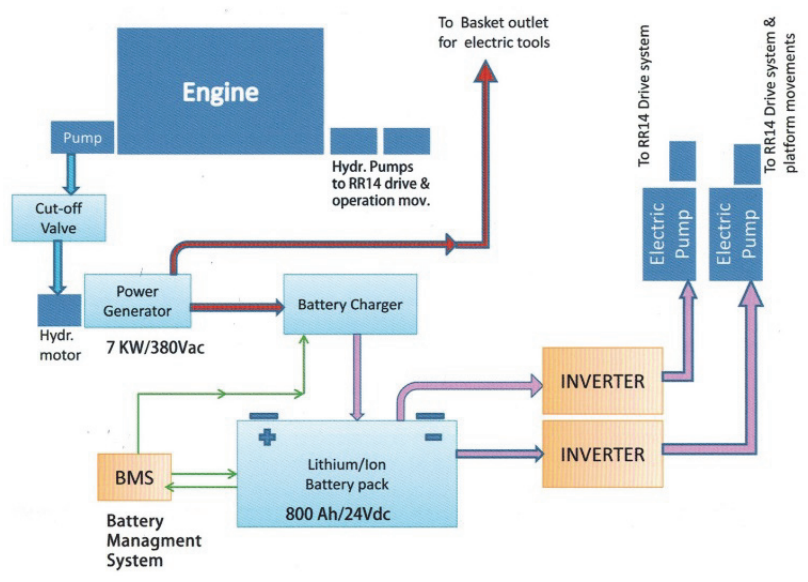

Fig. 10. The series hybrid drive setup of a Platform Basket cherry picker vehicle for on-rail operations [17].

Thanks to the use of the engine in series hybrid setup in this drive system, the manufacturer has significantly reduced the environmental damage caused by the vehicle's operation. This is the solution that has resulted in the popularity and competitiveness of the vehicle. It should be noted that in addition to the general directives and laws imposed by the European Union referred to as the Technical Specifications for Interoperability (TSI), all Member States continue to have diversified national laws, including noise emission limits, safety, operability, compatibility, efficiency or operating parameters. These directives are the obstacles to achieving full interoperability of rail systems in all the EU Member States. This is particularly important in the case of Poland because, as noted in the European Union Agency for Railways Interoperability Report for year 2015 [18], Poland is ranked 2nd among the countries with the greatest number of national rules and specifications in the EU. In Poland in the year 2015 there were 1113 country-specific rules for rail and road-rail vehicles (Fig. 11). For comparison, the only country with more national rules was the Netherlands (1270). It is more than double the average of the EU countries, especially 
the western countries like Germany (541) and France (574), many times more compared to Scandinavian countries like Sweden (319) or Norway (259). As a result of these differences in regulations and specifications between EU countries, it is difficult to provide rail vehicle operators in different countries with systems and vehicles that meet all these requirements uniformly. Hence, the technical solutions visible in the Platform Basket vehicles are tailored to meet these specifications and requirements for as many Member States as possible. For RR 14 EVO vehicles, the technical solutions have been selected to meet both the European and the country-specific requirements, in this case for Germany, Sweden, France and the United Kingdom.

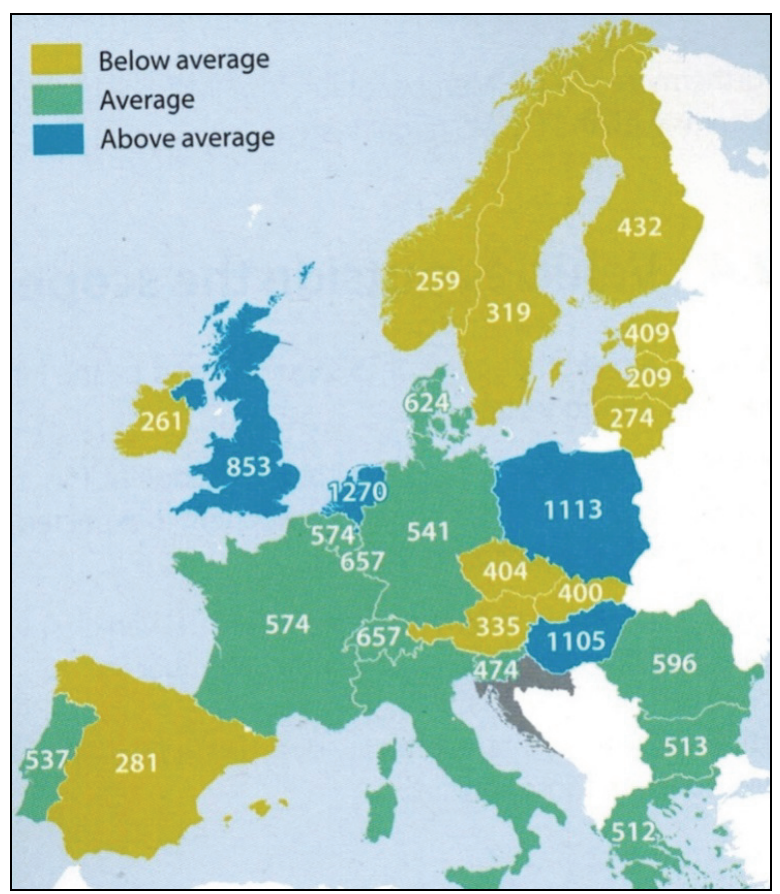

Fig. 11. National rules per EU member state in 2015 [18].

Another option available is the hybrid drive in serialparallel setup. This solution allows to power the wheels using either the internal combustion engine or the electric motor. This way it becomes possible to avoid the constraints of powering the wheels with an electric motor and, depending on the needs, transfer power to the wheels directly from the combustion engine (Fig. 12). This is of course at the expense of an increased fuel consumption and increased emissions, as it is not always possible to provide optimal operating conditions for the internal combustion engine when it is used to drive the vehicle directly. It is, however, possible to use its full power, which is a major advantage of this solution. Due to the operating characteristics of the series-parallel hybrid solution, it is used primarily in rail shunting vehicles. The CI internal combustion engine can still be regulated in such a way that it can be pushed towards its optimum operating conditions for as long as possible. As a result, the series-parallel hybrid drive system still offers significantly better emission rates than the conventional versions, including fuel consumption, which directly impacts the operating costs of hybrid vehicles. Hence, their purchase becomes an increasingly competitive offer for rail transport companies and operators.

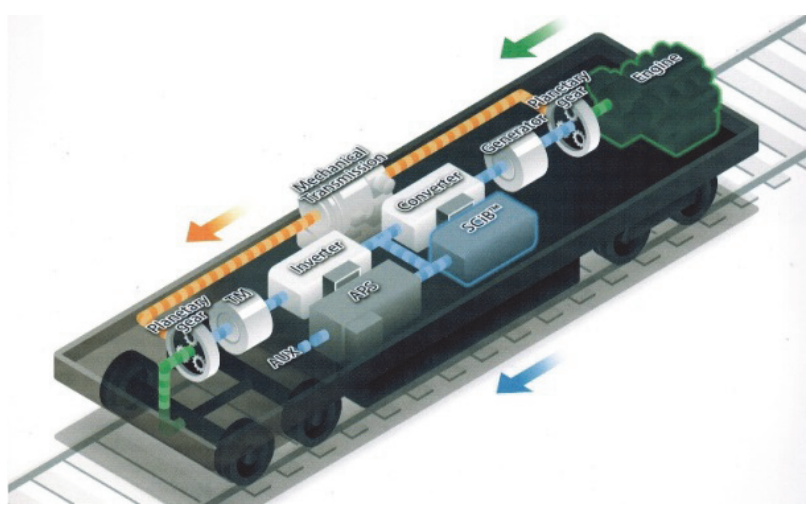

Fig. 12. Series-parallel hybrid drive design for a rail vehicle [16].

For passenger services, the most common solution is the Diesel-Electric Multiple Unit (DEMU). This solution makes it easier for the manufacturer to design a vehicle, allowing a design where several units can be combined and share certain elements, so that propulsion and axillary systems and elements can be deployed more ergonomically to maximize the space available to passengers. As an example, one of Woojin's latest designs utilizes the TeC1-M-T-TeC2 four-unit drive system (Fig. 13).

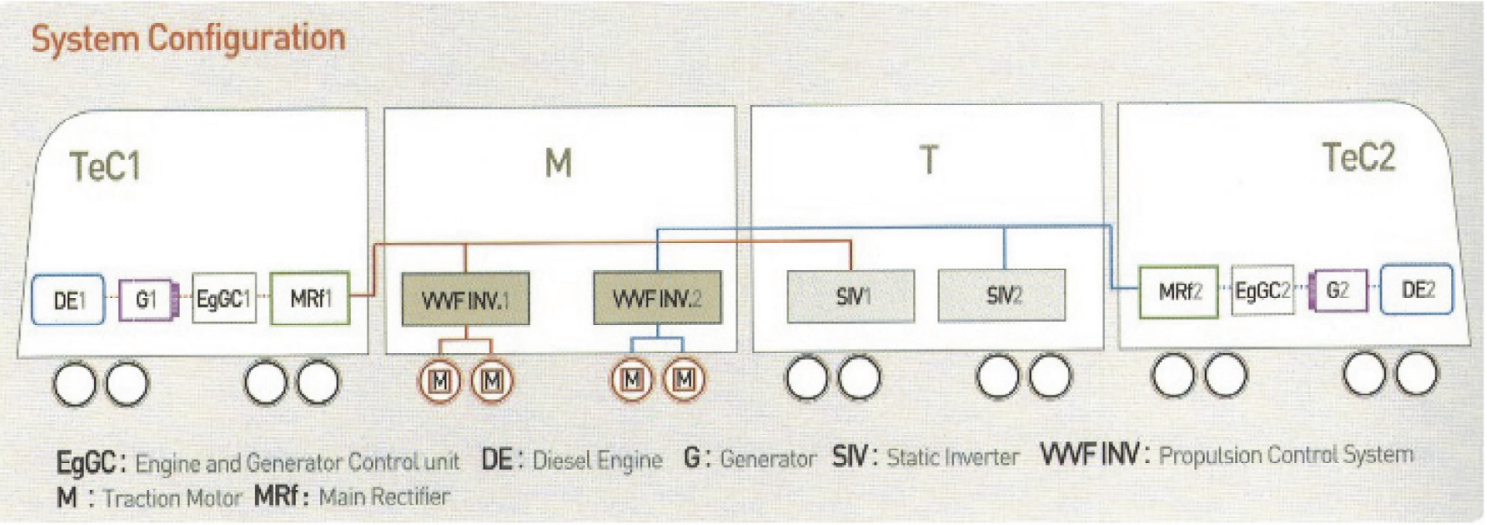

Fig. 13. Diesel-Electric Multiple Unit drive system setup designed and sold by Woojin [19]. 


\section{Rail vehicle fleet modernization possibilities}

Electric and hybrid drives are used in shunting vehicles increasingly more often. They are, however, less powerful, often requiring more operations to perform the same shunting work. Nevertheless, the costs and total harmful exhaust component emissions of each of these operations are significantly lower. This makes the solution even better than conventional shunting locomotives in terms of their environmental impact. The main factor in this case is the engine idling time, which is very high for maneuvering vehicles and constitutes a large share of the engine operating time [20]. Thus eliminating a key aspect responsible for a significant portion of the total exhaust emissions from an internal combustion engine in the engine working time.

The existing sales offers of new hybrid drive locomotives have only been on the market since relatively recently. The first hybrid locomotives were built on the principle of modernization of old conventional locomotives by replacing the drive unit. Over time, conventional diesel locomotives are expected to be replaced with electric and hybrid locomotives, at least to as high an extent as it is possible. Due to the costs associated with the modernization this process is slow in Poland, but it is noticeable nevertheless. Investments in this field are particularly important because of the very high average age of diesel locomotives used on Polish railroads. These locomotives need to be modernized or replaced with new ones, hence the widening range of new hybrid drive rail vehicles is a good and welcome sign. Still, the number of locomotives waiting for replacement or modernization is high. In Poland many older locomotives that would be discarded in other European countries are still being used, although retrofitting and modernization options are usually available (Fig. 14). An example of the process of vehicle modernization is the list of operated rolling stock offered by the PKP Cargo carrier and presented in Table 1. It is important to note that the total number of rail vehicles in operation decreased, which means that not all of the 424 rail vehicles taken out of service have been replaced with newer vehicles, such as rail vehicles with hybrid drives.

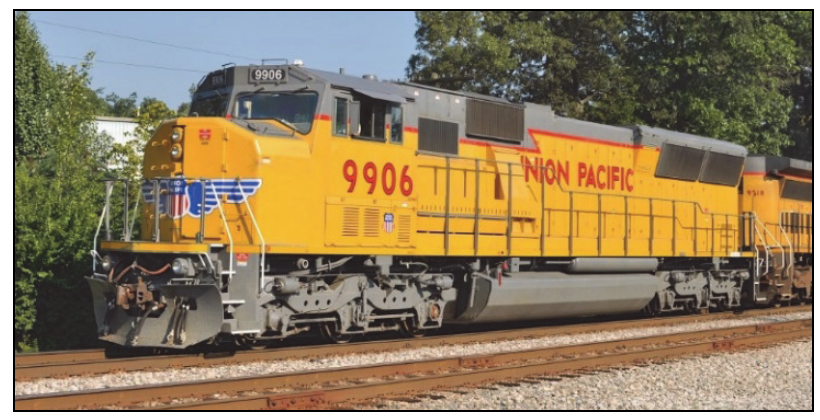

Fig. 14. SD59MX locomotive after retrofitting [21].

Numerous studies have researched the effects of diesel locomotive modernization on the vehicle's emissions, including the replacement of the engine unit with newer ones, the addition of new exhaust aftertreatment systems, and hybridization of the vehicle drive system [20, 22, 23]. Rail vehicle operators usually make the choice between these options based on the available funds, age and technical condition of the vehicles, the vehicle operating requirements and the necessity caused by the legal emission limits. All of these solutions can reduce harmful exhaust emissions and increase vehicle efficiency and profitability, but operators often limit themselves to the cheapest and easiest solutions out of all available options. It is therefore important for manufacturers to further develop hybrid drive rail technologies in order to allow the elimination of the conventional combustion engine drive vehicles from operation over time. This is also done through legislative means, urging operators to act in the name of environmental protection and reduce emissions of harmful exhaust components from the high power CI engines used to drive freight and passenger locomotives. Obtaining a $\mathrm{CO}_{2}$-free transport technology is one of the main and most ambitious objectives of the European Union, so further pursuit of ever cleaner and more efficient vehicle drives will remain an important aspect in the decision and law making process.

\section{Hydrogen-based drives}

In recent years vehicles with modern alternative drives are becoming more and more common in the offers of rail vehicle manufacturers. One of the main examples are hydrogen-fueled locomotives. These types of solutions have been around for some time now, but the costs associated with their purchase and operation effectively reduce the demand for these types of vehicles. Vehicles using fuel cell have very similar performance characteristics to electric rail vehicles and series hybrids. The difference is mainly the source of electric power. As with hybrid electric vehicles, the source of energy generated for the electric motor is an internal combustion engine operating in uniform speed and load ranges, and for vehicles powered with hydrogen fuels, the source of electric energy are the fuel cells. Combining hydrogen and oxygen in the fuel cells generates electricity based on instantaneous needs, controlled by the fuel cell hydrogen feed systems. This is by far one of the cleanest solutions available on the market, where the final product is the production of small amounts of water. Of course, the approach to pollutants generation should be holistic, hence the costs of producing, delivering and storing hydrogen as fuel for this type of a vehicle should be weighed into the calculation when assessing these new drive systems. In this case, hydrogen is produced by other companies, using mostly electricity from the power grid.

Keep in mind that energy losses occur at every step of production, processing, transportation, and ultimately operation. Despite the non-emissive nature of this type of fuel itself, its production can have a negative effect on the environment if its production uses electricity generated using fossil fuel based power plants. This problem is the same between hydrogen vehicles and electric vehicles. In addition, there are barriers to the full 
and expansive application of such technologies in rail transport. The main problem of these modern solutions are the initial costs of the vehicle as well as the infrastructure. Transporting and storing hydrogen as a fuel is much more difficult than other fuels, it is more expensive and more dangerous than handling diesel, petrol or even natural gas [24]. Hence, the fuel supply of hydrogen-powered rail vehicles also requires proper adaptation of the infrastructure to allow safe and efficient storage and refueling of hydrogen at the stations where it will be supplied to power the vehicles. It is very important in this case to protect the hydrogen fuel from leakage. The storage methods for hydrogen fuel are more demanding than for LPG fuel. The main problem is to provide air-tightness and stability from ambient temperature fluctuations for hydrogen that is normally stored in tanks at a pressure of 350-700 bar. The leakage for this kind of fuel tank involves the risk of explosion, while ensuring sufficient strength of the tank under this pressure requires the use of state-of-the-art high-strength and durability materials. The solutions currently on the market mostly use specialized roof tanks for hydrogen storage. This is the main place in the rail vehicles considered by manufacturers to be the safest and easiest to exploit in the existing rail vehicle designs (Fig. 15). It should be noted, however, that with the development of these technologies and with the increase in popularity of hydrogen as vehicle fuel new technologies and solutions will inevitably follow. Thus the current solutions are not truly optimized to take advantage of the new drive solutions, but the later iterations will build on the previous experiences, giving the manufacturers of vehicles the time they need to adjust their previous designs and concepts to the changes in vehicle drive technologies.

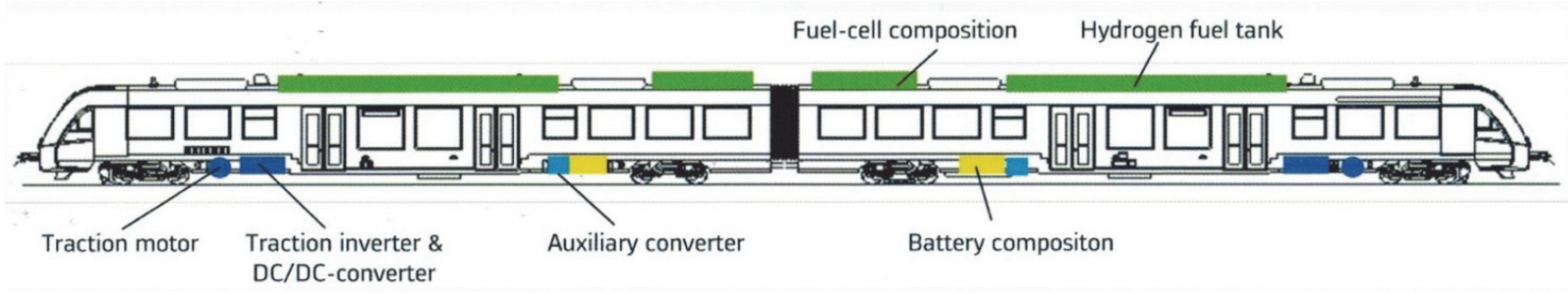

Fig. 15. An example of solving the problem of placing hydrogen tanks and fuel cells in Alstom's fuel cell locomotive design [25].

Table 1. Comparison of the change in vehicles in operation by the PKP Cargo [26].

\begin{tabular}{|c|c|c|c|c|c|c|c|c|c|}
\hline Number on 31.12 & SP32 & SP42 & ST43 & ST44 & ST45 & SU42 & SU45 & SU46 & Sum \\
\hline 2001 & 102 & 119 & 174 & 103 & - & 40 & 160 & 36 & 734 \\
\hline 2002 & 102 & 119 & 174 & 103 & - & 40 & 157 & 36 & 731 \\
\hline 2003 & 102 & 119 & 174 & 103 & - & 40 & 157 & 36 & 731 \\
\hline 2004 & 15 & 116 & 165 & 103 & - & 40 & 143 & 36 & 618 \\
\hline 2005 & 15 & 116 & 165 & 103 & - & 40 & 156 & 36 & 631 \\
\hline 2006 & 15 & 76 & 139 & 82 & - & 40 & 149 & 36 & 537 \\
\hline 2007 & 15 & 79 & 148 & 82 & - & 40 & 150 & 36 & 550 \\
\hline 2008 & 2 & 79 & 146 & 93 & - & - & 80 & 36 & 436 \\
\hline 2009 & 2 & 51 & 141 & 92 & 1 & - & 76 & 36 & 399 \\
\hline 2010 & 2 & 2 & 133 & 90 & 4 & - & 44 & 35 & 310 \\
\hline
\end{tabular}

\section{Conclusions}

Purely electric drives are most commonly used in medium-power locomotives on connections where electric traction or catenary is available. This is the simplest solution, but at the same time it significantly limits the use of this type of drive depending on the quality and availability of the appropriate infrastructure. As a result, a large number of conventional diesel locomotives remain in service. Engine and drive manufacturers are aware of this, so there are also numerous options offered of modernizing existing diesel locomotives. It should be noted that modernization was one of the easiest methods of introducing the first locomotives with hybrid drives to operation. Despite some initial costs, modernized rail vehicles are proving to be a good investment for train operators. While visible economic effects of such activities are expected over many years, the ecological effects are measurable fairly quickly [27].
Hybrid drives are also not the ultimate solution to the problem of high exhaust gas emissions. But they are now regarded as one of the main steps towards eliminating harmful substances from the exhaust gases emitted by means of transport. There are also a number of other new technologies that are gradually gaining popularity and competitive edge on the market. These include biofuel powered vehicles, or hydrogen powered fuel cells. Unfortunately, the latest of these technologies are not yet economically and practically usable on an industrial scale. Nevertheless, the future of transport, both rail and road-rail, should be considered. Hence, the main challenge facing the drive systems in the future is to create the right infrastructure for their full and proper exploitation. Due to the initial cost of such a project, cheaper and easier to use hybrid drives can fill the transition gap between the conventional and today's most technologically advanced rail vehicle drives. 


\section{References}

1. J. Markowski, J. Pielecha, R. Jasinski, T. Kniaziewicz, P. Wirkowski, E3S Web of Conferences 10, UNSP 00140 (2016), DOI: 10.1051/e3sconf/20161000140

2. Z. Korczewski, J. Rudnicki, Computational Methods in Marine Engineering VI 490-501 (2015)

3. C. Specht, J. Rudnicki, Polish Maritime Research 23, 20-27 (2016), DOI: 10.1515/pomr-2016-0028

4. J. Merkisz, W. Stawecki, Pojazdy Szynowe 3 (2015)

5. M. Michnej, M. Szkoda, Technika Transportu Szynowego 10, 38-40 (2007)

6. www.getransportation.com (2017)

7. Z. Juda, M. Noga, IOP Conference Series Materials Science and Engineering 148, UNSP $012042 \quad$ (2016), DOI: $\quad 10.1088 / 1757$ $899 X / 148 / 1 / 012042$

8. www.deere.pl (2017)

9. www.eickhoff-bochum.de (2017)

10. P. Fuc, P. Kurczewski, A. Lewandowska, E. Nowak, J. Selech, A. Ziolkowski, International Journal of Life Cycle Assessment 21, 1438-1451 (2016), DOI: 10.1007/s11367-016-1104-y

11. J. Merkisz, P. Lijewski, P. Fuc, M. Siedlecki, S. Weymann, Applied Engineering in Agriculture 31, 875-879 (2015)

12. J. Merkisz, P. Lijewski, P. Fuc, M. Siedlecki, A. Ziolkowski, IOP Conference Series-Materials Science and Engineering 148, UNSP 012077 (2016), DOI: 10.1088/1757-899X/148/1/012077

13. J. Merkisz, P. Lijewski, P. Fuc, S. Weymann, Eksploatacja i Niezawodnosc - Maintenance and Reliability 15, 364-368 (2013)

14. MTU company materials (2017)

15. P. Kortas, J. Kropiwnicki, Combustion Engines 3, 631-638 (2015)

16. Toshiba company website (2016)

17. Platform Basket company website (2017)

18. Progress with railway interoperability in the European Union, European Union Agency for Railways Interoperability (2015)

19. wjis.co.kr (2017)

20. R. Konsek, A. Mężyk, Maszyny Elektryczne 1, 1923 (2014)

21. www.up.com (2017)

22. M. Ehsani, Y. Gao, A. Emadi, Technology \& Engineering (2009)

23. K. Lewandowski, XX Międzynarodowa Konferencja Naukowa Pojazdy Szynowe 2012 (Poznan, 2012)

24. W. Gis, J. Pielecha, J. Waskiewicz, M. Gis, M. Menes, IOP Conference Series-Materials Science and Engineering 148, UNSP 012040 (2016), DOI: $10.1088 / 1757-899 X / 148 / 1 / 012040$

25. Alstom company website (2017)
26. PKP Cargo rail vehicles in operation (2017)

27. W. Morten, S.C. Jorgensen, K. Sorenson, International Journal of Vehicle Design 20, 1-4, (1998) 